\title{
PANORAMAS MÓVILES: EL TRAYECTO COMO IMAGEN
}

\author{
Javier Luri-Rodríguez \\ Universidad de La Laguna \\ luri.javier@gmail.com
}

\section{Resumen}

En el siglo xix la movilidad se convierte en un elemento central para la sociedad, la expansión de nuevos medios de transporte como el ferrocarril y nuevas producciones visuales basadas en el movimiento subrayan este protagonismo. Si en los panoramas, espectáculo decimonónico por excelencia, el movimiento estaba en el espectador que recorría físicamente la imagen, en los panoramas móviles el movimiento cambiaba de lado, ya que era la imagen la que circulaba ante los ojos del público. Este tipo de panoramas se sitúa en muchos aspectos entre la mirada panorámica y la cinematográfica y es especialmente interesante para describir ciertos cambios en la movilidad del espectador. Esta movilidad visual está relacionada con la vocación viajera del espectador, que buscaba en los espectáculos visuales sentirse transportado. Esta manera de viajar virtualmente a través de la imagen, así como otras características propias de esta visualización en movimiento como la opulencia visual o la rapidez e inmediatez del consumo visual, se fueron convirtiendo desde entonces en parte fundamental del carácter del consumidor de imágenes.

Palabras ClaVe: imagen, movilidad, panorama, arqueología de los medios.

MOVING PANORAMAS: THE PATH AS IMAGE

Abstract

In the XIX century, mobility became a central issue for societies. The expansion of new means of transportation such as the railway, as well as new visual productions centered around movement highlight this centrality. Whereas in the panoramas, quintessential nineteenth-century spectacle, the spectator was the one moving, physically walking around the image, moving panoramas switch the motion with the image moving before people's eyes. This type of panorama exists in many respects between the panoramic view and cinematography, and is of special interest for describing certain changes upon spectators' mobility. This type of visual mobility relates to spectators' travelling longings, who desired from visual spectacles to feel transported. This way of travelling virtually through images, as well as other characteristics of such moving imagery like visual opulence or immediacy of visual consumption, came to be since then a fundamental component of the consumption of visual media.

KeYwords: Image, Mobility, Panorama, Media archaeology.

DOI: https://doi.org/10.25145/j.bartes.2019-20.14.02

Revista Bellas Artes, 14; abril 2017-18, pp. 33-49; ISSN: e-2530-8432 
El movimiento determina el carácter de la imagen moderna mediante rasgos como la navegabilidad de la imagen esférica o la misma esencia dinámica del formato audiovisual. Explorar las conexiones entre movilidad y visualidad supone ahondar en dos de las características fundamentales de la cultura contemporánea; así lo destaca Nanna Verhoeff, quien ha definido como «régimen visual de navegación» la organización de esta movilidad visual presente en los distintos dispositivos audiovisuales que nos rodean ${ }^{1}$. Desde la imagen envolvente de los panoramas decimonónicos a los entornos de realidad virtual actuales, existe en el espectador una combinación de modelos epistemológicos y estéticos que convergen en una mirada curiosa, que ansía descubrir y conocer, y a la vez lúdica, que admira y se recrea con pasiva fascinación. Pero estas características en la mirada móvil también están presentes cuando la escena se despliega ante el público, cuando es la imagen la que se mueve, encarnando el viaje virtual del espectador: la imagen cinematográfica es otra forma de mirada panorámica, es otra forma de ingresar en la imagen para moverse por ella. Los panoramas, como primer espectáculo de masas, cambiaron en el siglo XIx la relación del espectador con las imágenes y es este siglo el que vio surgir el cinematógrafo, otro gran hito visual. Entre ambos medios encontramos a los panoramas móviles, y son estos un elemento crucial para seguir el rastro de la movilidad visual y describir el desarrollo de la imagen en su capacidad para hacer del espectador un turista virtual.

Esta evolución en la capacidad motora de la imagen ha estado ligada a la propia movilidad del individuo en sus medios de transporte y esta conexión supone una ilustrativa contextualización de ambos procesos viajeros. Así, los panoramas son una referencia crucial en el inicio de una transformación en la que la innovación tecnológica se alía con un fuerte deseo de expansión visual. Los nuevos espectáculos visuales y la popularización de los viajes gracias a los avances en medios de transporte participaron en este proceso, que se manifestó con claridad a partir del siglo XIX y que podríamos definir como "panoramización de la mirada». Dolf Sternberger habló de cómo el transporte moderno, y el ferrocarril en primer lugar, cambió la experiencia del mundo convirtiéndolo en un panorama.

El ferrocarril transformó el mundo de las tierras y los mares en un panorama que podría ser experimentado. [...] ahora que los viajes se habían vuelto tan cómodos y comunes, desvió la mirada de los viajeros hacia afuera y les ofreció el opulento alimento de las imágenes siempre cambiantes que eran lo único que se podía experimentar durante el viaje².

${ }^{1}$ Nanna Verhoeff, Mobile screens: The visual regime of navigation (Amsterdam: University Press, 2012).

${ }_{2}$ Cfr. Introduction: Why Railways, en Christian Wolmar, Fire and steam: A new history of the railways in Britain (London: Atlantic Books, 2007), pp. 1-20. 


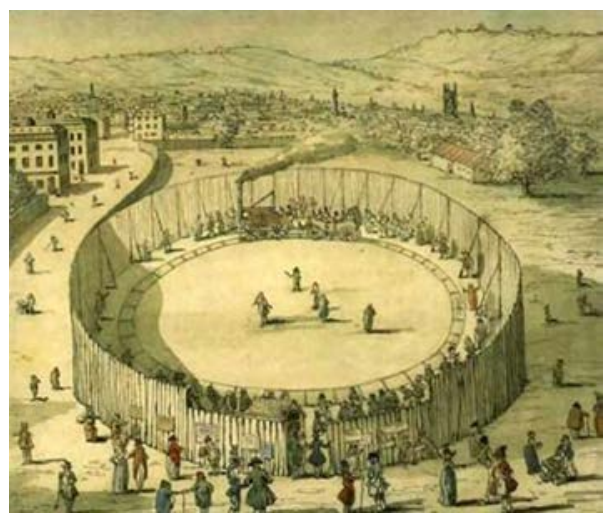

Fig. 1. Presentación de la locomotora de Richard Trevithick en Euston Square, Londres, 1809. Dibujo de Thomas Rowlandson. National Museum of Science and Industry, Londres.

Los panoramas representan a la perfección una nueva relación visual, caracterizada por una mirada voraz, envuelta por la imagen, de gran movilidad, pero a la vez distante y ajena, como la del viajero que observa a través de la ventanilla del tren.

En 1651, Luis XIV tenía como divertimento para sus invitados un pequeño tren en su jardín trasero. Era una especie de montaña rusa compuesta por un carro con ruedas que bajaba un valle sobre una pista de madera de 250 metros, saliendo de una pequeña estación ${ }^{3}$. Aunque la evolución de los trenes está relacionada fundamentalmente con el trasporte de mercancías y material, como en las minas, el gusto por la sensación de velocidad y el deseo de viajar impulsaron el desarrollo del medio de transporte desde sus inicios. En el siglo XIX es cuando se dieron las condiciones de conocimientos, técnicas y capital de inversión para que se terminara de definir un vehículo autopropulsado eficiente y seguro que hiciera posible el concepto de viaje en tren. Richard Trevithick fue uno de los principales partícipes de este logro, como pionero en el sistema de vapor de alta presión y creador de la primera locomotora de vapor sobre raíles a gran escala ${ }^{4}$. Cuando Trevithick presentó en 1809 su nueva locomotora, lo hizo montando un recinto que se llamó "Circo de vapor» (Steam Circus), en el que su locomotora "Atrápeme quien pueda» (Catch $\mathrm{Me}$ Who Can) daba un paseo circular por un módico precio (fig. 1). La exhibición de este nuevo invento, con su marcado carácter lúdico, muestra aspectos cercanos a los por entonces populares recintos circulares de los panoramas. A menos de media hora

${ }^{3}$ Cfr. Christian Wolmar, Fire and steam: A new history of the railways in Britain (London: Atlantic Books, 2007).

${ }^{4}$ Cfr. The first railways, en Christian Wolmar, Blood, iron, and gold: How the railroads transformed the world (London: Atlantic Books, 2009), pp. 21-42. 
de camino de la plaza donde se estaba exhibiendo el primer ferrocarril, el espectador podía contemplar los panoramas de Barker en su gran sala de Leicester Square 5 . El espectáculo de Trevithick pudo demostrar que la máquina de vapor podía ser más rápida que los carros de caballos, y con su teatral puesta en escena, también presentó al ferrocarril como un divertido invento con el que experimentar la velocidad.

Aunque el tren se irá consolidando principalmente como medio de transporte, esta función de espectáculo de contemplación y movimiento se mantuvo los años posteriores durante el desarrollo de la maquinaria ferroviaria. Aparte de las montañas rusas, durante muchos años también existieron en los parques de atracciones decimonónicos los ferrocarriles escénicos, en los que los clientes viajaban en pequeños vagones a través de recintos, túneles y jardines cuya decoración simulaba una variedad de lugares exóticos ${ }^{6}$. Si bien los panoramas clásicos, con su recinto circular por el que el espectador pasea su vista como un turista en un exótico mirador, son un elemento central en esa nueva esencia móvil de la imagen y en el componente viajero del espectador que en ese momento histórico se estaba forjando, la relación entre los trenes y los panoramas se hace especialmente visible con los panoramas móviles. En estos panoramas, el espectador no se mueve para recorrer la imagen, sino que es la imagen la que circula ante sus ojos.

En 1834, bajo el nombre de "Padorama», se expuso en Londres una representación del recorrido ferroviario de Liverpool a Mánchester en un panorama móvil acompañado de una escenografía inmersiva en la que los espectadores, sentados en vagones, podían ver pasar por la ventanilla las imágenes pintadas. Así se describe en el catálogo de la exposición:

Los motores y carruajes de esta exhibición son, por lo tanto, modelos correctos de aquellos en uso real, y la parte pictórica ha sido ejecutada por artistas de talento reconocido, a partir de bocetos hechos en el lugar; se han seleccionado todas las características principales y destacadas del ferrocarril de Manchester y Liverpool; se ha evitado una repetición de las vistas cuando la ruta no es interesante, y también se han omitido muchas de las partes aburridas de la ruta, de modo que los artistas no profesan exactitud en la distancia entre las partes representadas; aunque en otros aspectos desafían al juicio del público por la fidelidad de los puntos de vista seleccionados. Haber dado una representación continua ininterrumpida habría ocupado un espacio demasiado grande y, además, no habría sido interesante para el público? .

5 De Euston Square, donde se realizó la exhibición «Circo de vapor», a Leicester Square, donde el inventor de los panoramas tenía su sala en aquella época, hay unos 2,2 kilómetros en ruta a pie. El edificio donde se exhibían panoramas desde 1793 constaba de dos salas distintas con panoramas que se renovaban cada año.

${ }^{6}$ Cfr. Raymond Fielding, "Hale's Tours: Ultrarealism in the Pre-1910 Motion Picture», Cinema Journal, vol. 10, n. ${ }^{\circ} 1$ (1970): 42.

7 E. Colyer, Descriptive Catalogue of the Padorama: Of the Manchester and Liverpool railroad, containing 10000 square feet of canvass [sic], now exhibiting at Baker Street, Portman Square. Illustrated with twelve lithographic views, taken on the spot by artists of acknowledged talent (London: E. Colyer, 1834), 8. 
Llama la atención cómo se pone el acento en la capacidad de la imagen para adaptar las vistas del tren convirtiéndolas en una experiencia más placentera y cómoda para el espectador que el propio medio de transporte. En esa época empezaban a ser frecuentes imágenes que ilustraban los paisajes de distintos trayectos ferroviarios. Multitud de publicaciones con grabados de este tipo coincidían con esta promesa de facilitar las vistas al viajero-espectador ${ }^{8}$. Pero si los grabados podían capturar las escenas cambiantes de las ventanillas, aprehendiéndolas en imágenes fijas, el panorama móvil lograba capturar la propia movilidad de las escenas del viaje, ofreciendo sensación de movimiento al espectador. En la prensa de la época se recoge una descripción de la exposición que estuvo varios meses visitándose en una gran sala londinense:

Consiste en una vista panorámica en movimiento, que ocupa 10000 pies [más de 3000 metros] de lienzo, del ferrocarril de Manchester y Liverpool, y las partes más interesantes de la región que atraviesa. [...] El paisaje no es notable por la belleza pintoresca; pero los viaductos, puentes y túneles del ferrocarril producen un efecto sorprendente en el paisaje; y el conjunto transmite una idea vívida de esta vasta empresa?

En la Exposición Universal de París de 1900 la conexión entre los espectadores y los viajes se hizo manifiesta con multitud de espectáculos que simulaban viajes, como el Mareorama, donde se combinaba pintura panorámica en circulación con el balanceo de una plataforma para que el público gozara de un viaje virtual en barco, o el Cineorama, en el que una proyección cinematográfica múltiple rodeaba a los espectadores para simular un vuelo en globo.

En el pabellón ruso se dedicaron varias salas al ferrocarril transiberiano, pero sin duda la sala más popular fue aquella en la que el visitante podía ocupar uno de los cuatro vagones allí dispuestos a fin de hacerle sentir como un pasajero

${ }^{8}$ Pocos años antes del recorrido del Padorama de Liverpool a Manchester, en 1831, Isaac Shaw publicó «Vistas de los paisajes más interesantes del ferrocarril de Liverpool a Manchester», una serie de aguafuertes en varios volúmenes que mostraban detalladas vistas del paisaje que atravesaban los trenes. Por su parte, el destacado dibujante John Cooke Bourne reflejó el desarrollo del tren y su expansión por el territorio, retratando las excavaciones y construcciones de la incipiente industria ferroviaria. Con esta labor testimonial, el artista también ofrecía una imagen «fija» de las fugaces visiones de la ventanilla, ofreciendo al espectador, como hiciera Shaw, imágenes inmóviles en las que recrearse. En el prólogo de su libro de grabados La historia y descripción del Great Western Railway (1846), el propio Bourne explica su pretensión de mostrar las estaciones, puentes, túneles y viaductos a los pasajeros que pasaban fugazmente por estas construcciones y no tenían la oportunidad de apreciarlas debidamente desde sus vagones veloces. Durante la primera mitad de siglo fueron muy frecuentes las ilustraciones en láminas y libros, tanto de las líneas de ferrocarril como de los paisajes por los que estos pasaban. Cfr. John C Bourne, The history and description of the Great Western Railway (London: David Bogue, 1846).

9 Gustavus Arabin (ed.), «The Padorama», The Spectator, n. 307 (17-05-1834), 472, https:// books.google.co.uk/books?id=mzI_AQAAIAAJ\&dq=padorama\%20marshall\&pg=PA472\#v=onepa ge\&q\&f=false (consultada el 18 de mayo de 2018). 


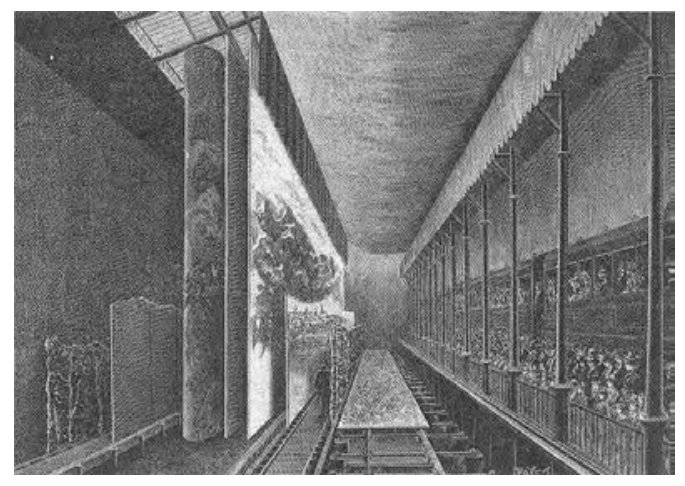

Fig. 2. Panorama del tren transiberiano en la Exposición Universal de París, 1900. Imagen: The Painted Panorama, de Bernard Comment, 2000 (p. 74).

de esa ruta internacional. A través de las ventanillas se podía contemplar el paisaje pasando mediante un complejo mecanismo en el que cuatro capas visuales surcaban la vista a distintas velocidades imitando la perspectiva y la velocidad del medio de transporte (fig. 2). En primer plano, una cinta transportadora movía a gran velocidad arena y piedras cerca de la ventanilla, y en planos más separados circulaban, menos veloces, arbustos y rocas, hasta que en la parte más alejada del espectador un inmenso y detallado panorama de variados paisajes se movía a una velocidad óptima para la calmada contemplación del pasajero virtual.

Sentados cómodamente en lujosos vagones, los visitantes vieron el lienzo de este panorama esbozado por M.M. Jambon y Bailly y, gracias a un ingenioso mecanismo, sintieron la completa ilusión de un viaje de Moscú a Pekín en media hora ${ }^{10}$.

Otra imagen móvil sobre la misma ruta ferroviaria se exhibió en ese pabellón. Fue la de Pavel Yakovlevich Pyasetsky, quien en otra sala mostró un extenso panorama que le fue encargado por la Administración del Ferrocarril Transiberiano $^{11}$ (fig. 3).

${ }_{10}$ Alfred Picard, Exposition universelle internationale de 1900 à Paris. Rapport général administratif et technique, vol. 5 (París: Imprimerie nationale, 1903), 80.

${ }_{11}$ Pyasetsky estuvo viajando en tren y tomando apuntes de sus vistas desde 1894 a 1899 , para componer nueve rollos de paisaje a acuarela pegados sobre lienzo en las que sintetizaba 10000 kilómetros de ruta en un enorme panorama de más de 850 metros de largo por medio metro de alto. Estos nueve rollos, que aún se conservan en el Museo Hermitage de San Petersburgo, muestran variados paisajes de distintas ciudades, puentes, escenas rurales, estaciones ferroviarias, etc. Varios artículos en la web del propio museo describen la pieza de Pyasetsky y su historia: «Restoration of Pyasetsky's Great Siberian Railway Panorama (1894-1899)» (2007) y «The State Hermitage and Russian Railroads (RZD) Sign a Protocol of Intent» (2014), publicados ambos en hermitagemuseum.org. 


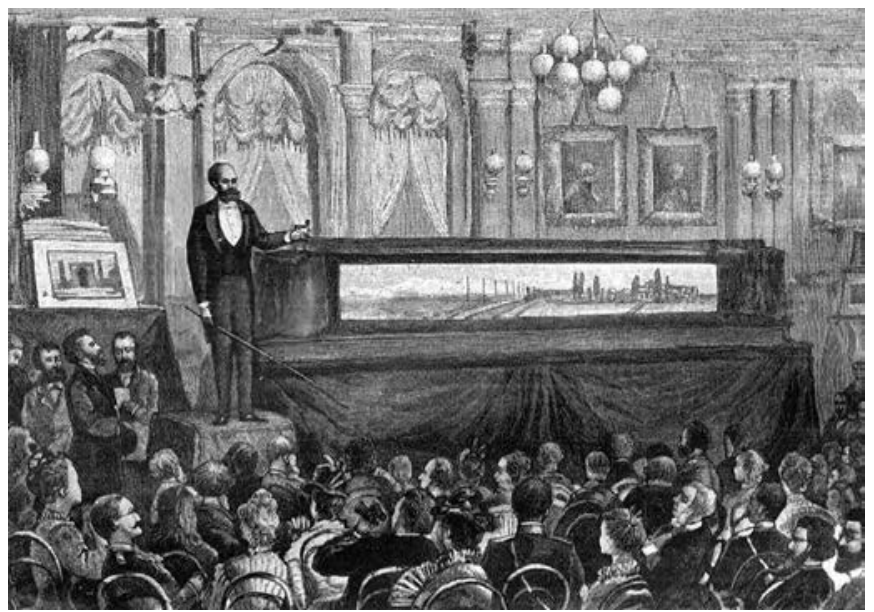

Fig. 3. Pyasetsky exhibiendo su panorama. Imagen: Niva magazine, n. ${ }^{\circ} 3.1895$ (p. 68).

En este caso el autor prescindió del entorno inmersivo. Los panoramas móviles, por lo general, no se exhibían con una compleja ambientación del espacio expositivo. Este tipo de imágenes extremadamente largas, normalmente enrolladas en cilindros a modo de papiro, solían tener un marco alargado entre los dos tramos del rollo para dejar ver una sección del paisaje mientras se desenrollaba. Con ello, quedaba enmarcada una vista en movimiento similar a la que se aprecia desde la ventanilla de un vagón de tren ${ }^{12}$. Estas imágenes móviles, cuyo desarrollo está relacionado con la irrupción de los medios de transporte modernos, son, según el historiador Stephan Oettermann, la variante más importante de los panoramas.

En esta versión, en lugar de una vista circular de 360 grados, el artista tomó una larga tira de lona y recreó un tramo de paisaje entre dos puntos, como se le podría aparecer a un viajero desde un carruaje, un vagón de ferrocarril o un barco de vapor por un río. Esta nueva forma de arte representa una reacción a los avanzados medios de transporte que se estaban desarrollando en toda Europa durante la Revolución Industrial. La creciente velocidad a la que se hizo posible viajar ahora dio lugar a una forma completamente nueva de ver el paisaje, que ha sido llamada precisamente "panorámica». La nueva forma de «asimilar» un paisaje que pasa encontró su equivalente estético en el panorama extendido ${ }^{13}$.

${ }^{12}$ En la pintura tradicional china son comunes las largas pinturas enrolladas, como la célebre $A$ lo largo del rio durante el Festival de Qingming $(528 \times 24,8 \mathrm{~cm}$. Museo del Palacio de Beijing), del artista Zhang Zeduan (1085-1145). No obstante, este tipo de pintura está pensada para que el espectador vaya desenrollando con sus propias manos la imagen durante su visualización. 1997), 63

${ }^{13}$ Stephan Oettermann, The panorama: history of a mass médium (New York: Zoone Books, 
Bernard Comment, otro experto en panoramas del s. XIX, también admite la importancia de este tipo de panoramas como instauradores de una nueva forma de visualidad. Según este autor, el panorama móvil «provocó un cambio radical en relación con el panorama circular, un cambio que involucró otra lógica», al romper con la necesidad de una arquitectura especialmente adaptada y representar el espacio en forma de «barrido lateral» ${ }^{14}$. Sin embargo, es desde la arqueología de los medios de Erkki Huhtamo desde donde más se ha destacado y puesto en contexto la relevancia de este tipo de imágenes ${ }^{15}$. $\mathrm{Al}$ reubicar este espectáculo visual dentro de la historia de la imagen en movimiento y destapar su verdadero significado cultural, este autor ha estudiado y descrito los panoramas móviles como un fenómeno importante que supuso conectar lo local con lo global, actuando como un pionero medio de comunicación de masas audiovisual.

En 1848, en San Louis, John Adams Hudson presentó un lienzo de más de 1200 metros de largo para representar un viaje de cuatro días y tres noches por el río Hudson. El éxito del espectáculo le llevó de gira durante diez meses, llegando a atraer a más de mil espectadores en algunas jornadas. Al año siguiente, William Burr pintó las escenas de un amplio viaje que abarcaba los Grandes Lagos, las cataratas del Niágara y los ríos de San Lorenzo y Saguenay. Este tour virtual estaba lleno de detalles cambiantes, como transiciones de la noche al día o diferentes condiciones climáticas. Se exhibieron doscientos pases de este panorama en Nueva York y mil en Boston, alcanzando unos dos millones de visitantes ${ }^{16}$. En Europa este tipo de imágenes en movimiento también fueron un divertimento muy popular: Albert Smith, por ejemplo, describió su ascenso por el Mont Blanc en un panorama móvil que combinaba desplazamiento horizontal y vertical, y que se mostró 2000 veces en la Egyptian Hall de Londres entre 1852 y 1858. Los contenidos del programa de esta ascensión se fueron actualizando de vez en cuando, y hasta se llegaron crear numerosos productos secundarios como juegos de mesa o panoramas móviles en miniatura para promocionar el espectáculo ${ }^{17}$.

${ }^{14}$ Bernard Comment, The Painted Panorama (New York: Harry N. Abrams, 2000), 65.

15 Según este autor, los panoramas móviles han sido injustamente eclipsados por los clásicos panoramas circulares, relegándolos a una función de variante menor por varios motivos, entre los que destaca el papel de la historia del arte a la hora de construir un relato protagonizado por un arte «elevado» más cercano a los pintores de panoramas de grandes formatos albergados en importantes construcciones arquitectónicas, y dejando así de lado la amplia producción de panoramas móviles creada en formatos y técnica más modestos. Los panoramas móviles, dirigidos mayoritariamente a áreas alejadas de las grandes urbes y a gentes de menos recursos, no han gozado de una justa atención por parte de investigadores y teóricos: para tal historia del arte revisionista, el panorama de 360 grados ha sido un tema adecuado, porque se encuentra en algún lugar entre las tradiciones clásicas de la pintura y la arquitectura, los espectáculos visuales populares y los emergentes medios de comunicación. Erkki Huhtamo, "Global Glimpses for Local Realities: The Moving Panorama, a Forgotten Mass Medium of the 19th Century», Art Inquiry. Recherches Sur les Arts, n. 4 (2002): 193-228.

${ }^{16}$ Cfr. Bernard Comment, The Painted Panorama (New York: Harry N. Abrams, 2000), 63-64.

${ }^{17}$ Cfr. Ralph Hyde, Panoramania! The art and entertainment of the "all-embracing" view (London: Trefoil in association with Barbican Art Gallery, 1988), 146-149. 


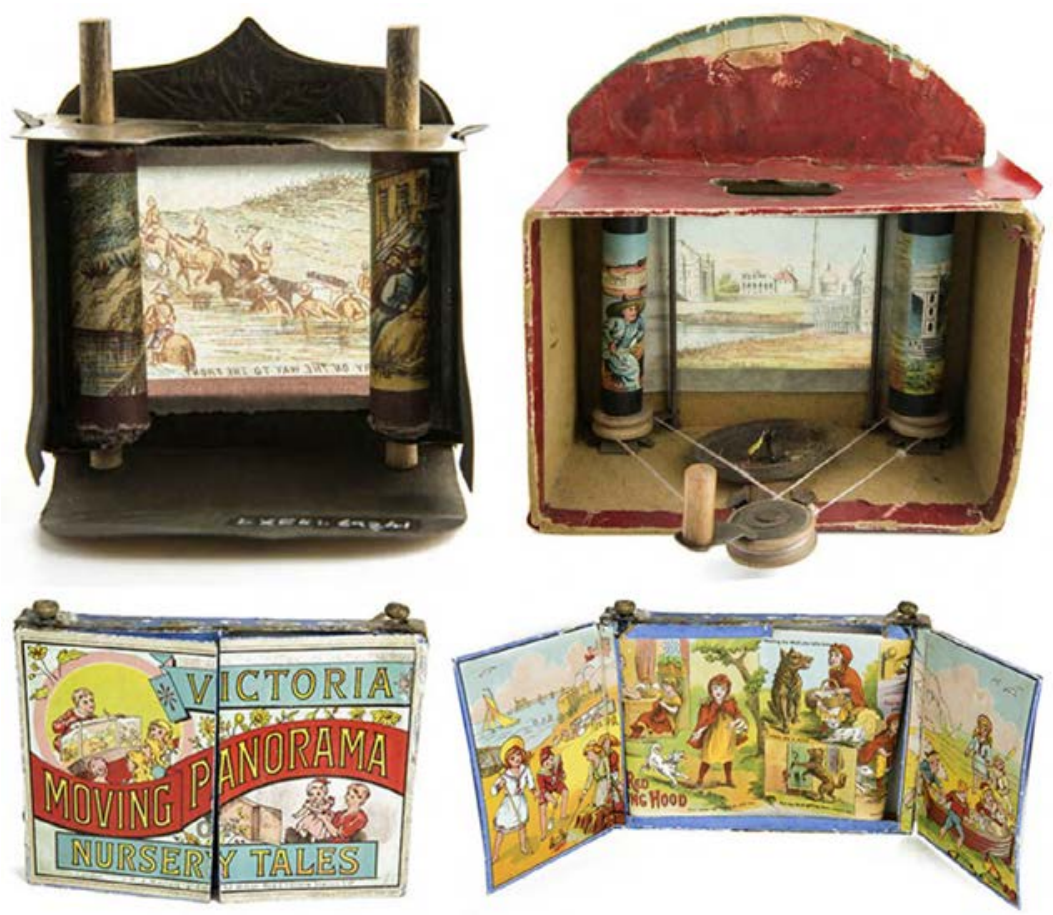

Fig. 4. Juguetes de panoramas móviles. Guerra de Sudáfrica, Maravillas del mundo y (abajo) Cuentos de guardería. Imágenes publicadas en Victorian Popular Culture (1779 a 1930), del portal Adam Matthew Digital, 2011.

Bastan estos pocos ejemplos para evidenciar la importancia de los panoramas móviles entre los espectáculos de la época, pero lo realmente relevante es la difusión que llegaron a alcanzar. Por distintas cuestiones como su naturaleza portátil o su producción más barata, la presencia de los panoramas móviles fue mayor que la de los panoramas circulares ${ }^{18}$. Estas imágenes enrolladas se extendieron durante el siglo xix por teatros y grandes salas, pero también, y sobre todo, por pequeñas ferias; e incluso adoptaron formatos muy pequeños, distribuyéndose como juguetes o divertimentos domésticos (fig. 4).

18 «Aunque no existe evidencia estadística exacta, las cifras de producción de panoramas en movimiento, la densidad de sus exposiciones, el número de localidades en las que se mostraron y el número total de sus espectadores excedieron con creces los de las panorámicas circulares. [...] particularmente en los Estados Unidos, la mayoría de los contemporáneos habrían asociado la palabra 'panorama' directamente con el panorama en movimiento, no con el panorama circular». Erkki Huhtamo, "Global Glimpses for Local Realities: The Moving Panorama, a Forgotten Mass Medium of the $19^{\text {th }}$ Century", Art Inquiry. Recherches Sur les Arts, n. ${ }^{\circ} 4$ (2002): 8. 
Aunque muchos se expusieron en las principales ciudades, se trataba de un medio fundamentalmente ambulante que acercaba las imágenes a zonas rurales y comunidades reducidas. La mayoría de los espectáculos eran llevados por companías pequeñas, negocios personales o familiares. Como medio ambulante, estuvo inmerso en las tradiciones centenarias de entretenimiento itinerante, compitiendo con compañías de teatro, magos, autómatas y espectáculos de linterna mágica. Estas exhibiciones efímeras fueron suficientemente frecuentes y variadas como para no considerarlas versiones menores de los panoramas móviles más elaborados diseñados para los recintos de las grandes ciudades. Más bien, este nomadismo marcó la identidad de estos espectáculos. La movilidad de estas imágenes era doble: por un lado, la experiencia se basaba en el movimiento de las pinturas para articular una narración fluida y, por otro, su itinerancia las hacía capaces de viajar hasta lugares recónditos de la geografía en busca de su público.

Pero el carácter viajero de estas imágenes móviles no era la única diferencia con los panoramas esféricos. Ambos buscaban transportar al espectador a lugares lejanos, pero no por idénticos medios.

Los panoramas circulares enfatizaban la inmersión en un lugar o evento, mientras que los panoramas en movimiento se basaban más en la narración y las combinaciones de diferentes medios de expresión. La sensación de viajar virtualmente de un lugar a otro, o de un tema a otro, era importante para este último, pero la inmersión sin fisuras no era el objetivo principal ${ }^{19}$.

Aunque el viaje solía estar de una u otra forma presente en estas imágenes, la mayoría de las veces no se trataba de simular la experiencia viajera como ocurría en los ejemplos de las exposiciones del tren de Liverpool a Mánchester o del Transiberiano. Como se ha indicado, no se desaprovechaba la posibilidad de omitir momentos aburridos del viaje y recrearse en los mejores paisajes, por lo que, incluso en esos ejemplos más cercanos a la simulación, ya se podía entrever la aptitud creativa de este formato, su tendencia a componer relatos en base a diferentes escenas seleccionadas. En definitiva, el panorama móvil, más que el centro de un sistema de simulación, fue una nueva forma de narración audiovisual con una revolucionaria manera de representar el paso del tiempo y el espacio.

La presencia de un marco que contenía las imágenes y la ambientación sonora en las exhibiciones definieron un nuevo tipo de mirada panorámica, una nueva forma de recorrer la imagen. Pianistas o incluso bandas de música acompañaban a los panoramas móviles en sus viajes ${ }^{20}$ (fig. 5).

19 Erkki Huhtamo, Illusions in motion: media archaeology of the moving panorama and related spectacles (Cambridge: The MIT Press, 2013), 8.

20 «La música jugó un papel vital en cualquier panorama en movimiento, siendo utilizada para manipular las emociones de la audiencia. Aunque muchos showman se conformaron con un pianista, las firmas más grandes, los Marshall en la década de 1820 y los Pooles de la década de 1880, usaban bandas de música. Cada una de las 'orquestas' de los Pooles (como pomposamente las llama- 

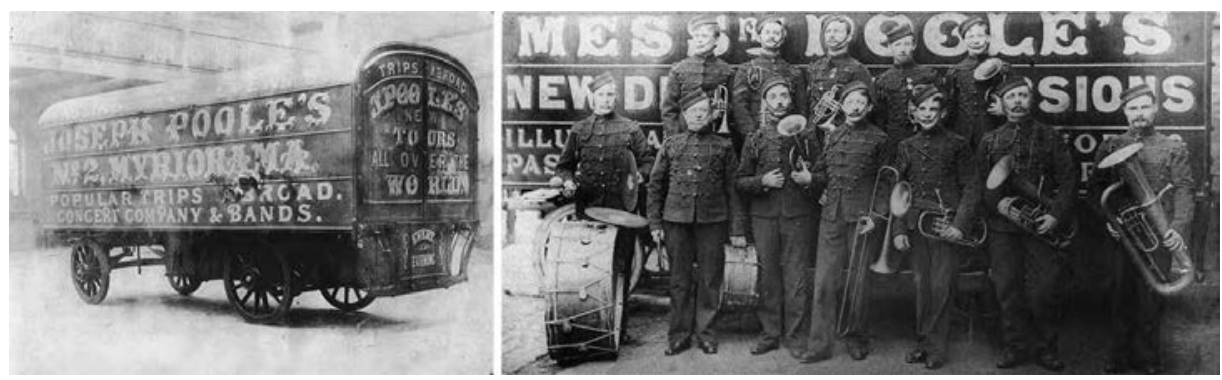

Fig. 5. (Izquierda) Vehículo para transportar los panoramas móviles de Poole (Myriorama); como en otros vehículos de feria y circo, el medio de transporte servía también como anuncio móvil. (Derecha) Banda de Poole; la música era una parte fundamental del espectáculo. Imágenes: HYDE, Ralph. Panoramania! The art and entertainment of the "all-embracing" view. London: Trefoil in association with Barbican Art Gallery, 1988 (p. 153).

Aparte de la música, fue especialmente importante el papel de un narrador durante las exhibiciones ${ }^{21}$. Con esta combinación de discurso oral, música y otros efectos escénicos, estos espectáculos se especializaron en la descripción de lugares y la narración de viajes y aventuras ambientadas con gran efectismo. Mientras se hacían rodar los rollos de imagen, la historia allí representada se iba recreando en un formato que, más que pictórico, resultaba audiovisual (fig. 6).

La «naturaleza» del panorama en movimiento no puede entenderse focalizándose exclusivamente en el lienzo (que en la mayoría de los casos es imposible de todos modos). El espectáculo tenía muchos aspectos escenográficos y circunstanciales. Elementos como la velocidad de giro, efectos especiales adicionales y la interacción entre imagen, narración, música y efectos de sonido contribuían al efecto total, como lo hacía el contexto físico de visualización ${ }^{22}$.

Estas representaciones narradas y con efectos sonoros, en las que la imagen se iba desenrollando para guiar la narración, parecen haberse producido por primera

ban) normalmente consistía en diez músicos». Ralph Hyde, Panoramania! The art and entertainment of the "all-embracing» view (London: Trefoil in association with Barbican Art Gallery, 1988), 152.

${ }^{21}$ Con el estadounidense John Banvard, y su panorama del río Misisipi en 1840, se inició la «edad de oro» de los panoramas móviles. Presumía de tener tres millas de largo (4828 metros), pero también destacó por la narración oral que acompańaba a sus imágenes, repleta de descripciones, chistes y poesía. "A partir de Banvard, ningún espectáculo panorámico estuvo completo sin un orador, más tarde llamado cicerone, y el éxito o el fracaso de una pintura dependería al menos tanto del ingenio y del vocabulario exuberante de este hombre como de las cualidades del panorama como obra artística». Ralph Hyde, Panoramania! The art and entertainment of the "all-embracing» view (London: Trefoil in association with Barbican Art Gallery, 1988), 133.

${ }^{22}$ Erkki Huhtamo, "Global Glimpses for Local Realities: The Moving Panorama, a Forgotten Mass Medium of the 19th Century», Art Inquiry. Recherches Sur les Arts, n. ${ }^{\circ} 4$ (2002): 13. 

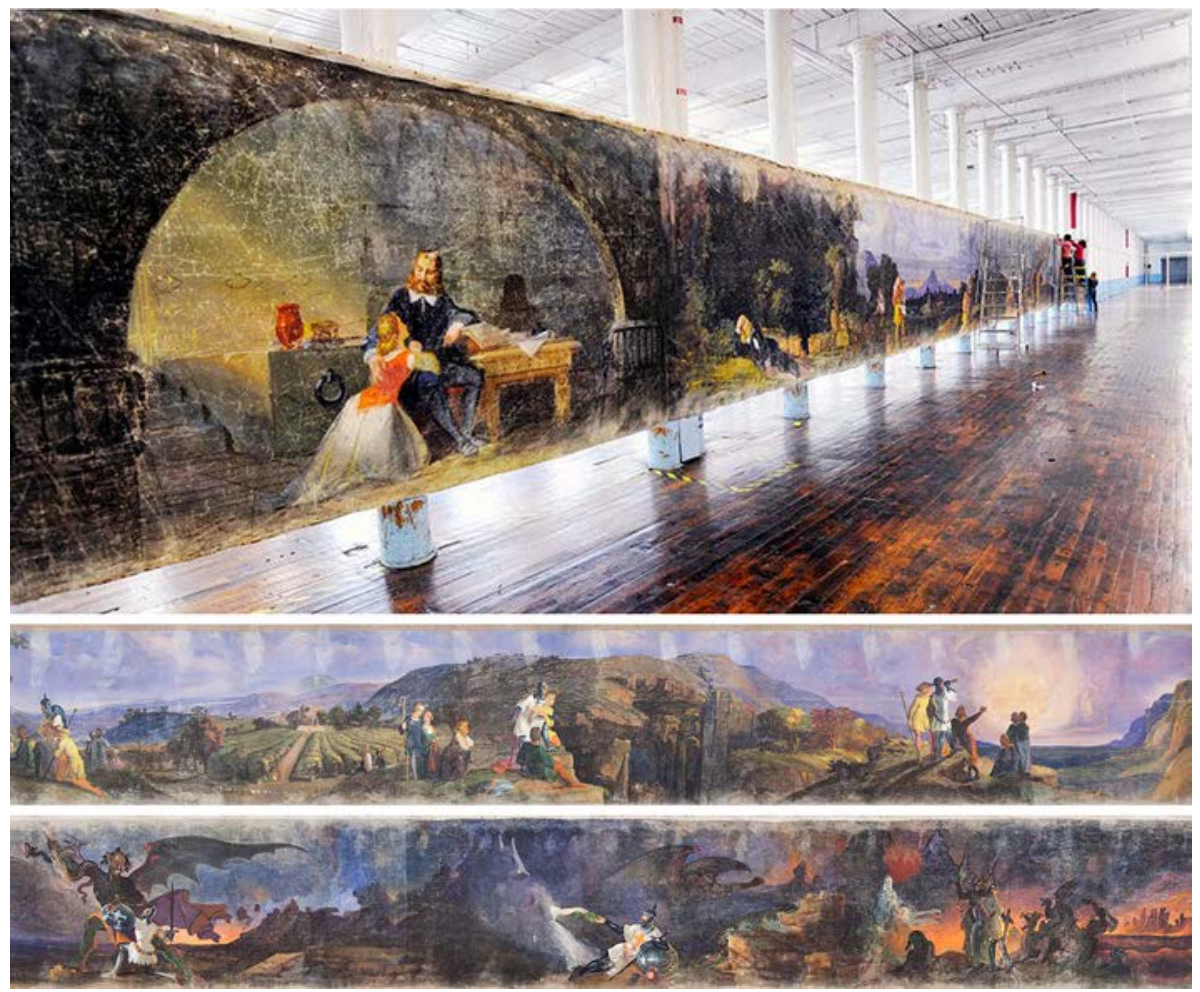

Fig. 6. Panorama móvil El progreso del peregrino (detalles), de Joseph Kyle y Jacob Dallas. Mide unos 244 metros y estuvo recorriendo el condado de York de 1851 a 1864. Actualmente en Museo Saco (NY). Imágenes: www.sacomuseum.org.

vez en Inglaterra a partir de 1818 con el nombre de «Peristrephic Panorama». Con este nombre, los hermanos Marshall, conocidos hombres del espectáculo, representaban temas de interés periodístico o documental, como batallas recientes, un naufragio, una expedición polar o la coronación del rey Jorge $\mathrm{IV}^{23}$. Unos años después, el mismo nombre de "Peristrephic» se extiende por diversos países, incluido Estados Unidos, para anunciar panoramas móviles.

${ }^{23}$ La forma cóncava de sus imágenes, junto con el hecho de que algunas de sus primeras representaciones fueran hechas en lugares especialmente acondicionados deja claro que los panoramas esféricos fueron la principal influencia de estas imágenes en movimiento. Por otro lado, se adelantaron a los posteriores dioramas, que representarían eventos similares, pero mediante una escenografía más tridimensional y menos móvil. A diferencia de los panoramas en los que se basaron, pero al igual que los dioramas que aparecieron después, los panoramas móviles de los Marshall pronto mostraron la capacidad híbrida de ubicación permanente y nómada. 
Una detallada descripción de uno de estos espectáculos en Dublín fue hecha por un viajero que visitó la ciudad en 1828:

... me fui a casa, cuando me tentó la publicidad de un «Panorama peristrephic» de la batalla de Navarino. Esta es una vista muy divertida; y da una idea tan clara de ese "evento adverso", que uno puede consolarse a sí mismo por no haber estado allí. Entras en un pequeño teatro, se abre el telón y detrás de él se descubren las imágenes que representan, al completo, la sucesión de los diversos incidentes de la lucha. El lienzo no cuelga hacia abajo, sino que se estira en un semicírculo convexo, y se mueve lentamente sobre rodillos, de modo que las imágenes cambian de forma casi imperceptible, y sin interrupción entre escena y escena. Un hombre describe en voz alta los objetos representados; y el trueno distante de cańones, la música militar y el ruido de la batalla aumentan la ilusión ${ }^{24}$.

En esta descripción destaca el hecho de que las imágenes se sucedan con cambios progresivos ininterrumpidos, totalmente fundidos.

Esta narratividad audiovisual con escenas que se desarrollan en un continuum también está ampliamente documentada en un panorama móvil de Otis Allen Bullard, realizado entre 1846 y 1850, que representaba la ciudad de Nueva York. En una imagen de casi 2000 metros cuadrados de lienzo dividida en varios rollos, el panorama móvil de Bullard suponía un espectáculo en el que durante dos horas los espectadores disfrutaban de un recorrido urbano que incluía vistas a pie de calle mostrando grupos de gente y rincones variados, pero también vistas aéreas para apreciar construcciones y extensas panorámicas de la metrópoli. Así mismo, aparecían retratos de personalidades de la ciudad, con lo que la diversidad de puntos de vista era total ${ }^{25}$. La variedad de escenas ronda las 154 vistas distintas de aproximadamente dos por seis metros cada una, pero todas integradas en un mismo recorrido fluido. Esta producción audiovisual, que contaba con narrador, viajó por todo el país, exhibiéndose en pequeñas salas sociales, escuelas urbanas, iglesias, así como en muchas ciudades importantes y en

${ }^{24}$ Hermann Pückler-Muskau, Tour in England, Ireland, and France: In the Years 1828, 1829: with Remarks on the Manners and Customs of the Inhabitants, and Anecdotes of Distinguished Public Characters: in a Series of Letters (London: E. Wilson, 1832), 160-161.

25 Esta ruta escénica de seis millas comenzó «a los pies de Cortland Street», siguió por "West [y Whitehall] Street alrededor de Battery» y prosiguió “"por Broadway hasta la cabecera de Union Park". Bullard representó a lo largo de esta ruta todos los barcos de pasajeros y mercancías, barcos de vapor, canales y barcazas, baños flotantes y capillas, cada variedad de vida frente al mar, los establecimientos comerciales de Broadway, iglesias, hoteles, etc., los atascos interminables y la vida callejera variada de personas de todos los estratos sociales. Luego esbozó lugares individuales y temas de particular interés en otras partes de la ciudad: "muchos de los edificios públicos y privados más importantes... parques y plazas públicas... procesiones imponentes y espléndidas", como escenas adicionales y significativas para el panorama. Incluía vistas aéreas de toda la ciudad y el puerto, tomadas desde puntos elevados, y unas cuantas vistas de calles laterales, algunas también desde lugares altos, "una gran parte de la ciudad se ve mirando hacia abajo a medida que se revela en una perspectiva audaz"». (Las comillas del artículo hacen referencia a distintas publicaciones sobre el espectáculo recogidas en periódicos locales entre 1850 y 1858). Joseph Earl Arrington, "Otis A. Bullard's Moving Panorama of New York City», New-York Historical Society Quarterly, vol. 44 (1960): 314. 
grandes salas de espectáculos. La exhibición se consideró de gran interés como entretenimiento, pero también fue considerada como una buena forma de instruir a los jóvenes. Destacando este valor educativo, los espectadores llegaron a afirmar que era «el tipo de pintura más veraz e instructiva jamás ejecutada»" ${ }^{26}$ gracias a su naturaleza divulgativa ${ }^{27}$ y lúdica, se consideró que «fue el nuevo medio para promover la educación masiva y el entretenimiento público en todo el país ${ }^{28}$. Se estima que un millón de personas visitaron el panorama móvil de Bullard entre los años 1850 y 1858 en Estados Unidos y Canadá. Con todo ello, es indudable el papel del panorama móvil en la difusión del formato audiovisual. Fue un influyente producto cultural, no sólo como espectáculo precinematográfico, sino como pionero medio de comunicación de masas.

La forma de contemplar la pintura en movimiento de los panoramas móviles nos recuerda a los dibujos de Albert Robida, cuando imaginaba con humor el futuro de su época. En su novela $E l$ siglo veinte, de 1883, ambientada en un futuro no muy lejano (1952), Robida cuenta la manera en la que sus protagonistas visitan el Museo del Louvre: la visita es realizada desde unos vagones de tranvía que recorren el recinto a buen ritmo (fig. 7).

¡Descansemos nuestras mentes por un momento en el Templo de las Artes! sugirió Helen, llegando a las puertas del Louvre.

Aquí está el tranvía circular, dijo Bernabette; haremos el recorrido a través de las obras maestras a gusto...

En efecto, los últimos avances realizados por un Ministro de Bellas Artes enemigo de la rutina, un tranvía encantador y elegante, impulsado por la electricidad, ahora corre en rieles a través de todas las galerías del museo. [...]

Este viaje a través de las Artes toma solo una hora. En una hora, los visitantes han recorrido la historia de las Bellas Artes, desde la hermosa época griega y romana hasta la gran revolución de los modernistas o los fotopintores; en una hora, el visitante más ignorante puede, si tiene ojos y oídos, saber casi tanto como el crítico más trascendental ${ }^{29}$.

${ }^{26}$ Ibidem, 321.

27 Las cualidades divulgativas o educativas de los panoramas móviles eran muy valoradas. El panorama móvil «El arca de Noé pictórica» de Betts, por ejemplo, era un juguete que servía para que los pequeños aprendiesen los nombres de los animales, que se podían ver pasar por parejas al rodar el panorama, hasta entrar en el Arca. El «Panorama Colonial de Nueva Zelanda» de Brees, abierto en 1849, promocionó la colonia británica mostrando imágenes idealizadas de sus paisajes y sus gentes. A Brees, como ingeniero principal y topógrafo de la Compañía de Nueva Zelanda, le interesaba llevar allí inversores, con lo que se explica cierto componente propagandístico. Valorando su carácter instructivo, The Times dijo del espectáculo: «Hará más para promover la emigración que mil discursos y resoluciones». Richard Daniel Altick, The shows of London (Cambridge: Harvard University Press, 1978), 426.

${ }_{28}$ Joseph Earl Arrington, op. cit., 320.

29 Albert Robida, Le Vingtième Siècle (Paris: Georges Decaux, 1883), 48. 


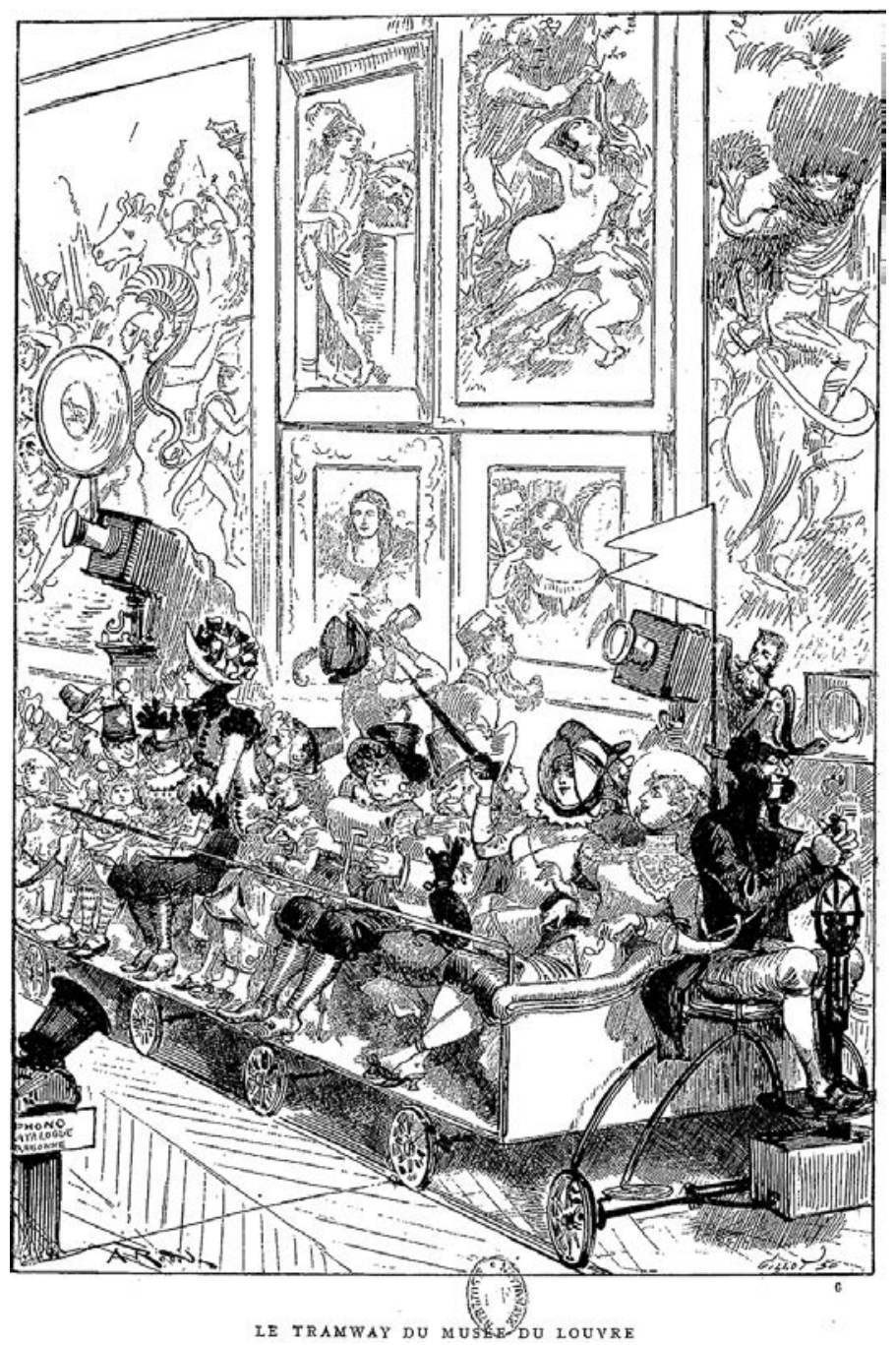

Fig. 7. El tranvía del museo del Louvre, ilustración de la novela El siglo veinte, de Albert Robida, 1883 (p. 49).

Robida, que vivió en ese siglo XIX de los trenes, los panoramas, la velocidad y los primeros medios visuales de masas, aun desde la fantasía y el humor, fue capaz de reflejar en su obra los anhelos y expectativas del observador de su época. El público es representado sobre ruedas, dotado de cámaras y prismáticos, en una nueva forma de consumo y dominio visual conquistado por la velocidad. La tecnificación de la mirada acarrea aquí una opulencia visual pretendidamente caricaturesca, que vista hoy pierde toda apariencia exagerada. Antes de la aparición del cine- 
matógrafo, pero en plena época de panoramas, este autor parece haber intuido la nueva relación que se estaba empezando a forjar entre el espectador y las imágenes.

Los panoramas esféricos son el espectáculo visual más popular del siglo XIX, en ellos el movimiento del espectador es fundamental para la contemplación. El siglo siguiente el cine se convertiría en el nuevo espectáculo visual para las masas, y en él el movimiento también es consustancial ${ }^{30}$. En ambos existe una manera de contemplar basada en el flujo visual, en un acontecer temporal y espacial en el que el espectador debe sumergirse para apreciar la obra, para irla recorriendo. El panorama móvil como híbrido de ambos muestra los aspectos comunes del medio panorámico y el cinematográfico como la multiplicidad y el dinamismo de la mirada, e ilustra una transición en la que un nuevo espacio representativo se estaba abriendo paso. Con los panoramas móviles, el espectador dejó de andar para que fuera la imagen la que le transportase.

Si la revolución del siglo pasado en el transporte vio el surgimiento y la popularización gradual del vehículo motorizado dinámico (tren, motocicleta, automóvil, avión), la revolución actual en la transmisión nos lleva a su vez a la innovación del vehículo definitivo: el vehículo audiovisual estático, que marca el advenimiento de una inercia conductual en el emisor/receptor que nos lleva desde la célebre persistencia retiniana que permite la ilusión óptica de proyección cinemática a la persistencia corporal del «terminal-hombre»; un requisito previo para la súbita movilización de la ilusión del mundo, de un mundo entero, telepresente en cada momento, el propio cuerpo del observador se convierte en la última frontera urbana ${ }^{31}$.

El carácter de la mirada contemporánea se forma en gran medida en la época de los panoramas, donde la imagen empezó a ofrecer al espectador lo que estaba reclamando como pasajero: movilidad y alejamiento. Un asiento con vistas panorámicas al mundo.

RECIBIDO: enero de 2019; ACEPTADO: noviembre de 2019

30 «Los contemporáneos podían ser sensibles a una evolución que arrastraba a las artes consigo y cambiaba el estatuto del movimiento, inclusive en la pintura. [...] Con ello, la danza, el ballet, el mimo pasaban a ser acciones capaces de responder a accidentes del medio, es decir, a la repartición de los puntos de un espacio o de los momentos de un acontecer. Todo esto comulgaba con el cine. Desde la aparición del sonoro, el cine será capaz de hacer de la comedia musical uno de sus grandes géneros, con el 'baile-acción' de Fred Astaire desplegándose en cualquier sitio, en la calle, en medio de los coches, a lo largo de la acera. Pero ya en el cine mudo Chaplin había arrebatado al mimo del arte de las poses para convertirlo en mimo-acción. [...] el cine pertenece de lleno a esta concepción moderna de movimiento». Gilles Deleuze, La imagen-movimiento: Estudios sobre cine 1 (Barcelona: Ediciones Paidós, 1984), 20-21.

31 Paul Virilio, Open Sky (London: Verso, 1997), 11. 


\section{BIBLIOGRAFÍA}

Altick, Richard Daniel. 1978. The shows of London. Cambridge: Harvard University Press.

Arrington, Joseph Earl. 1960. Otis A. Bullard's Moving Panorama of New York City, New-York Historical Society Quarterly 44: 308-355.

Bourne, John C. 1846. The history and description of the Great Western Railway. London: David Bogue.

Colyer, E. 1834. Descriptive Catalogue of the Padorama: Of the Manchester and Liverpool railroad, containing 10,000 square feet of canvass [sic], now exhibiting at Baker Street, Portman Square. Illustrated with twelve lithographic views, taken on the spot by artists of acknowledged talent. London: E. Colyer.

Comment, Bernard. 2000. The Painted Panorama. New York: Harry N. Abrams.

Deleuze, Gilles. 1984. La imagen-movimiento: Estudios sobre cine 1. Barcelona: Ediciones Paidós.

Fielding, Raymond. 1970. Hale's Tours: Ultrarealism in the Pre-1910 Motion Picture, Cinema Journal, vol. 10, n. ${ }^{\circ} 1: 34-47$.

Gustavus, Arabin (ed.). 1834. The Padorama, The Spectator 307 (17 de mayo): 472. https://books. google.co.uk/books?id=mzI_AQAAIAAJ\&dq=padorama\%20marshall\&pg=PA472\#v=on epage\&q \&f=false (consultada el 18 de mayo de 2018).

Huntamo, Erkki. 2002. Global Glimpses for Local Realities: The Moving Panorama, a Forgotten Mass Medium of the 19th Century, Art Inquiry. Recherches Sur les Arts 4: 193-228.

Huнтамо, Erkki. 2013. Illusions in motion: media archaeology of the moving panorama and related spectacles. Cambridge: The MIT Press.

Hyde, Ralph. 1988. Panoramania! The art and entertainment of the "all-embracing" view. London: Trefoil in association with Barbican Art Gallery.

Oettermann, Stephan. 1997. The panorama: history of a mass medium. New York: Zoone Books.

PICARD, Alfred. 1903. Exposition universelle internationale de 1900 à Paris. Rapport général administratif et technique 5. París: Impremiere nationale.

PüCKler-Muskau, Hermann. 1832. Tour in England, Ireland, and France: In the Years 1828, 1829: with Remarks on the Manners and Customs of the Inhabitants, and Anecdotes of Distinguished Public Characters: in a Series of Letters. London: E. Wilson.

Robida, Albert. 1883. Le Vingtième Siècle. Paris: Georges Decaux.

Schivelbusch, Wolfgang. 1986. The railway journey: The industrialization of time and space in the nineteenth century. California: Univ of California Press.

Verhoeff, Nanna. 2012. Mobile screens: The visual regime of navigation. Amsterdam: University Press.

Virilio, Paul. 1997. Open Sky. London: Verso.

Wolmar, Christian. 2007. Fire and steam: A new history of the railways in Britain. London: Atlantic Books.

Wolmar, Christian. 2009. Blood, iron, and gold: How the railroads transformed the world. London: Atlantic Books. 
